\title{
EL MINICUENTO EN LA LITERATURA COLOMBIANA
}

\section{Resumen}

El presente artículo constituye un esbozo histórico acerca del minicuento y de la importancia que ha venido adquiriendo este género en la literatura colombiana. Su proceso analítico se expresa en torno a cinco aspectos a saber: una evaluación de la situación actual del género; los antecedentes cuentísticos en Colombia, que se encuentran en El Camero de Juan Rodríguez Freyle; la publicación de Suenan Timbres, obra del poeta Luis Vidales con la cual se inicia el minicuento como género literario; su limitada creación y difusión en la etapa del cuarenta al sesenta; el período de plena consolidación y difusión en la década del setenta; y, la perspectiva que tiene este tipo de creación en nuestros días.

\section{Abstract}

The present article constitutes a historic overview of the short short story and of the importance that this genre has been acquiring in the Colombian literature. Its analytic process is expressed around of five aspects, such as: an evaluation of the current situation of the genre; the precursor of the short story, which is found in El Carnero, written by Juan Rodríguez Freyle; the publishing of Suenan Timbres, written by Luis Vidales and with which the short short story is begun as a literary genre; its limited creation and dissemination in the period of the 40s to the 60s; the period of full consolidation and dissemination in the 70s; and, the perspective that this kind of creation has in our days.

\section{Palabras claves:}

Minicuento, Suenan Timbres, minificción, Ekuóreo, Luis Vidales.

El minicuento, minificción ${ }^{1}$ o ficción brevísima, ha adquirido un notable interés en los últimos años. Con alguna frecuencia están surgiendo en diferentes países

\footnotetext{
* Profesor Universidad Pedagógica Nacional

1 Minificción o ficción brevísima es el nombre que adoptan algunos críticos e investigadores, entre ellos Edmundo Valadés, Lauro Zavala, Graciela Tomassini y Stella Maris Colombo, para nominalizar un tipo de texto caracterizado por la breved ad y un estatuto ficcional, sin estar relacionado directamente con una clase de superestructura determinada. Para las dos investigadoras últimamente mencionadas, existe diferencia entre minificción y minicuento, pues, mientras consideran la primera como una cat egoría transg enéri ca, que recubre un área más vasta que la del minicuento, ya que trasciende las restricciones genéri cas; la segunda, comparte
} 
importantes antologías, novedosos estudios, investigaciones y propuestas didácticas, para el anális is y asimilación de sus aportes a la literatura y a otros géneros discursivos, como ocurre con el presente trabajo, que además de constituir una indagación acerca del desarrollo seguido por este tipo de creación en la literatura colombiana, hace parte de las reflexiones que pretenden his toriarlo, elaboradas en el marco del Proyecto de investigación titulado Ambiente hipermedial para el desarrollo de la didáctica literaria a partir del minicuento, que se adelanta actualmente en la Universidad Pedagógica Nacional.

\section{Tradición cuentística y movimiento minificcional}

Colombia no ha sido ajena al movimiento del ingenio poético encapsulado, inmersa en una tradición cuentística fundacional que se retrotrae al Carnero, (1636-1638) de Juan Rodríguez Freyle, obra en la cual aparecen los primeros relatos breves o historielas ${ }^{2}$, precursoras del cuento hispanoamericano. En este proceso creador durante el siglo XIX, son reconocidos diferentes cuentistas de gran trascendencia como Tomás Carrasquilla, José María Rivas Groot, Lorenzo Marroquín, Jesús del Corral y Francisco Gómez Escobar (quien se firmaba como Efe Gómez), y los exponentes más sobresalientes del siglo XX son Jorge Zalamea, Manuel Mejía Vallejo, Octavio Amórtegui, Hernando Téllez, Alvaro Cepeda Samudio, Andrés Caicedo, Marvel Moreno, Gabriel García Márquez, Nicolás Suescún, Luis Fayad, Helena Araujo, Policarpo Varón, Humberto Valverde, Ricardo Cano, Fanny Buitrago, Darío Ruiz y Roberto Burgos, entre los cuales los diezúltimos mencionados todavía se encuentran en plena actividad.

A manera de síntesis, teniendo en cuenta la condición de artículo de este escrito, quizás sea pertinente señalar cuatro momentos fundamentales en el proceso creador que ha seguido este tipo de textos brevísimos en la literatura colombiana: Un primer momento, que puede considerarse como fundacional, sería la

semas que justifican su empleo como designaciones equivalentes para aludir a un tipo de texto breve y sujeto a un esquema narrativo (1996: 83-84).

Por su parte Edmundo Valadés al referirse a la natural eza de la creación breve explica: “La minificción no puede ser poema en prosa, viñeta, estampa, anécdota, ocurrencia o chiste. Tiene que ser ni más ni menos eso: minificción. Y en ella lo que vale o funciona es el incidente a contar. El personaje, repetidamente notorio, es aditamento sujeto a la historia, o su pretexto. Aquí la acción es la que debe imperar sobre lo demás" (1990).

2 Con el término Historiela, tomado del italiano, el cual se asimila al de novela, novella, noticia, historia o cuento breve, denomina Oscar Gerardo Ramos (1968) las veintitrés narraciones con estilo de cuento que constituyen el núcleo de El Carnero. Así, explica Ramos: "Una tendencia de índole cuentística pervade muchos relatos. Estos serían entonces historielas y Rodríguez Freyle sería un historielista. Veintitrés narraciones, con estilo de cuento, constituyen el eje de El Carnero. Si se las llama historielas en vez de cuentos, es porque no son rigurosamente historias, ni leyendas sino hechos presumibles de historicidad, tal vez tejidos con leyenda y matizados por el genio imaginativo del autor que toma el hecho, le imprime una visión propia, lo rodea con recursos imaginativos y, con agilidad, le da una existencia de relato corto. En este sentido pues, las historielas se asemejan al cuento: son, por tanto, precursoras del cuento hispanoamericano, y Rodríguez Freyle, como historielista, se acerca a la vocación del cuentista.[...]". (Págs, 33-38). Con esta propuesta de Ramos coinciden otros críticos, entre ellos Darío Achury, Hector H. Orjuela y Silvia Benso. 
publicación de Suenan timbres, (1926) del poeta Luis Vidales; el segundo, que puede ser entendido como su etapa de maduración, se caracteriza en un comienzo por la poca consideración que tiene el minicuento, y, posteriormente, por su desarrollo creativo en la obra de importantes escritores, (etapa del cuarenta al sesenta). Se trata de un período en el que la minificción supera las limitaciones en cuanto a los espacios de difusión, que dejaban de ser insignificantes o marginales, en diferentes periódicos y revistas, y accedía a la página del libro, en antologías u obras exclusivamente compuestas por minicuentos. Además, el progreso en su recepción, cada vez en aumento, era un síntoma del interés que iba despertando.

Una tercera etapa, que puede apreciarse como el período de plena madurez y auge del minicuento, se presenta entre los años setenta y ochenta, lapso caracterizado de una parte, por el que resurgimiento de importantes figuras de las letras, quienes se interesan por referentes como la oralidad, la cultura popular y los conflictos sociales, y de otra parte por la creación de la Revista Ekuóreo, publicación dedicada exclusivamente al estímulo y difusión del minicuento.

Un cuarto período, estaría caracterizado por el reconocimiento y aceptación que ha adquirido la creación breve en nuestros días y los múltiples canales de difusión que se emplean para ponerla al alcance del lector como los textos escolares, las ventas ambulantes, las filas de los cineclubes, los concursos en periódicos y revistas, los vehículos de servicio público, la radio, las antologías o libros individuales, por nombrar algunos espacios.

Por tratarse apenas de una síntesis del estudio que adelantamos en torno a la historia de este tipo de creación, nos referiremos en forma breve y panorámica a cada una de estas etapas:

\section{Luis Vidales: Fundador}

Pese a que muchos de los es critores colombianos han incursionado en la creación de cuento breve y algunos han dado a la publicidad libros de minicuento, una revisión histórica de esta forma de ficción conduce a reconocer por antigüedad y estilo de escritura autoconsciente, al poeta Luis Vidales como el fundador de este tipo de creación breve en Colombia.

Con su libro Suenan Timbres, publicado en 1926, Vidales no solo se puso en sintonía con los vanguardistas del continente americano sino que instauró en Colombia una escritura heteróclita, caracterizada por la extrema brevedad, el humor, la paradoja y la ironía; la resistencia a ser ubicada en el horizonte genérico literario de la época y su cercanía a la sentencia, el poema, el epígrafe, el apólogo, la greguería y el chiste, entre otros.

Suenan Timbres es un libro compues to formalmente por una autobiografía titulada "Confesiones de un aprendiz del siglo" y cuatro capítulos denominados: "Los importunos"; "Poemas de yolatría"; "Curvas" y "Estampillas". La curiosa estructura 
del texto está dada porque la mayor parte de su contenido - por no decir que su totalidad, excluyendo los primeros textos que son cuentos breves y unos pocos poemas líricos- está integrado por minificciones, si nos atenemos a la caracterización propuesta por Tomassini y Colombo.

Aunque en Colombia, y especialmente en Bogotá, apenas empezaba a conocerse su poesía por aquella época, gracias al descubrimiento que de ella hiciera en 1922 el escritor Luis Tejada, las creaciones de Vidales tendrían mayor resonancia en el exterior, especialmente en Buenos Aires, donde se desarrollaba un efervescente movimiento vanguardista, y hasta donde llegaron los ecos de su poesía. Lo anterior le permitió convertirse en el único poeta colombiano incluido en la famosa antología de 1926, seleccionada y prologada por Jorge Luis Borges, Vicente Huidobro y Alberto Hidalgo, titulada Indice de la nueva poesía americana, donde el poeta colombiano figura al lado de 61 poetas más de nueve países, entre ellos, Francisco Luis Bernárdez, Leopoldo Marechal, Pablo de Rocka, Pablo Neruda, Luis Cardoza y Aragón, Carlos Pellicer, César Vallejo y Macedonio Fernández, quien puede considerarse uno de los fundadores de la escritura minificcional en este continente.

En 1922, cuando el escritor Luis Tejada presentó al poeta Vidales, profetizaba la acogida que tendría su poesía con estas palabras: "Se que sus versos no irán a gustar todavía a esa gran masa de público rutinizado en el viejo sonsonete, sin alma ni médula, que nos dan diariamente quienes confunden la belleza con la sonoridad vacua y pretenden hacer poesía escalonando adjetivos, armonías y superficiales colores, en visión pobre por sólo ser descriptiva". (Citado por Isaías Peña, 1986). Este vaticinio habría de cumplirse posteriormente con la aparición de Suenan Timbres, un libro que reunía parte de la poesía y la prosa de Vidales, y que despertó ataques e indiferencia. Solo 50 años después logró obtener el reconocimiento merecido, el cual sobrevendría en 1976, fecha en que se publicó la segunda edición y "todos los jóvenes lo aclamaron, porque era su poesía, la del siglo XX, la de la nueva música, la de las ciudades tecnificadas y llenas de oficinas y de fábricas, lejos de los arreboles y llantos románticos o modernistas". (Peña: 1986, pág. 17).

A comentar la particular naturaleza de sus textos integrados en Suenan Timbres, el poeta Luis Vidales explicaba: "Contra lo que pueda creerse mi renovación poética comenzó por la prosa... Ni cuento ni poema en prosa, algo así como un nuevo género, pero sin pretensiones de serlo". Así, se fundamentaba la ingeniosa escritura que imprimía levedad y renovación a la narrativa colombiana, caracterizada por discursos dedamatorios nacionalistas y grandilocuentes que encontraban bastante resonancia en $L a$ vorágine, la novela popular de aquél momento, y en la poesía con marcado acento telúrico. 


\section{La Minificción en Perspectiva}

Pese al espíritu renovador con que apareció inicialmente Suenan timbres, no encontró el suficiente eco para consolidar entre los jóvenes escritores de la época el "nuevo género", situación que determinó la limitada atención y difusión del minicuento durante los siguientes catorce años aproximadamente, hasta que a partir de la década del cuarenta cambió dicha condición.

El destino de la minificción, tipo de creación esencialmente constitutiva de Suenan Timbres, es incierto en aquella época, pues como señalan Bustamante y Kremer (1994), el minicuento aparece "relegado entre cuentos de mayor paginaje, en rincones olvidados de revistas, cumpliendo un papel de relleno, de viñetas poco consideradas por los lectores". Solo hasta 1940-1960 empieza una producción continuada de minicuentos que se aprecia en las obras publicadas por Jorge Zalamea, Jorge Gaitán Durán, Alvaro Cepeda Samudio y Manuel Mejía Vallejo, entre otros.

\section{Consolidación y Auge del Minicuento: Nacimiento de Ekuóreo}

Entre los años setenta y ochenta se presenta en la literatura colombiana un importante movimiento hacia la creación y difusión de las formas narrativas breves. El minicuento, que ya evidenciaba cierta regularidad en la producción artística de algunos escritores, se consolida en esta etapa y se convierte en un "nuevo género" al que se le dedica atención no solo desde el punto de vista creativo sino de difusión y vinculación con otros géneros literarios. Escritores como David Sánchez Juliao, quien había incursionado en la modalidad del "cuentocassette" con historias de la cultura popular que reivindicaban la tradición oral como El Pachanga y El Flecha, experimenta también con la escritura de minicuento en su libro El Arca de Noé (1976).

Así mismo, Jairo Anibal Niño, otro escritor ubicado en la cultura popular, quien configura en algunas creaciones breves los problemas sociales, publica por aquella época dos importantes libros de minicuento: Toda la vida y Puro Pueblo (1979), aunque desde mucho tiempo atrás venía dando a conocer este tipo de creación en revistas y periódicos. Otro escritor que se ubica en este período es Elkin Obregón, quien con su serie de caricatura titulada Los invasores logró una importante relación entre el Cartoon y la historia breve.

Uno de los acontecimientos más sobresalientes en el estímulo de la creación y en la difusión del minicuento en el período reseñado es el surgimiento de la revista Ekuóreo, publicación especializada en recopilar y difundir textos de este género. Su entusiasta actividad durante algunos años no solo llamó la atención de muchos escritores y lectores colombianos sino que trascendió las fronteras para llegar al conocimiento de uno de los más importantes impulsores del minicuento en His panoamérica: el maes tro Edmundo Valadés. 
En su artículo "Ronda por el cuento brevísimo" (1990) que escribió para la revista argentina Puro Cuento, el maestro mexicano se refiere al papel pionero que cumplió la revis ta Ekuóreo en el fomento y difusión del minicuento en Colombia, y señala cómo dicho papel estaba en sintonía con el auge que por aquella época había adquirido este tipo de creación en Hispanoamérica. Ekuóreo se constituía en una publicación que a nivel colombiano sintetizaba las nuevas formas de escritura liviana y versátil con que los escritores pretendían revelar una nueva sensibilidad estética esencialmente urbana, relacionada con el lenguaje de la publicidad, el video clip, y otras formas discursivas propias de los medios de comunicación y caracterizadas por la brevedad.

A revisar la historia de Ekuóreo no deja de llamar la atención el núcleo humano que promovió su nacimiento, pues, inevitablemente este dejaría la huella en su creación: se trata de la juventud universitaria, que en su momento expresaba rebeldía no solo contra la situación social del país sino contra los discursos estereotipados y retóricos, que se expresaban en el quehacer literario. Al respecto dice Guillemo Bustamante, uno de sus fundadores y co-directores: "en tal contexto -integrado también por el hecho de ser estudiantes de literatura, y con fiebres "adolescentiles" de escritores-, nos propusimos hacer una chapola mamagallista; algo que diera espacio para el humor, para no tomarse las cosas tan en serio". (2001: 2-3).

Por su parte Harold Kremer, el otro fundador y co-director explica respecto a Ekuóreo:

"El primer número de Ekuóreo se publicó en Cali en febrero de 1980 y el último apareció en noviembre de 1992. Ekuóreo se propuso difundir y fomentar la escritura del minicuento. Tuvo dos períodos: durante el primero, que se inició en la Universidad Santiago de Cali, se publicaron en total 29 números, del 1 al 30 . Un segundo período se inició y culminó en la Universidad del Valle, donde se publicaron 7 números, del 1 al 7. La palabra Ekuóreo, del adjetivo ecuóreo ("del mar"), fue sugerida por Eduardo Serrano Orejuela -entonces profesor de la Universidad del Valle-. En sus 37 números, Ekuóreo publicó un total de 139 cuentos cortos, varios de los cuales fueron tomados de novelas, libros de poesía y filosofía, entrevistas, canciones y periódicos" (Bustamante, 2001: 1).

En consonancia con quienes creaban y difundían el minicuento también surgieron reflexiones teóricas que apuntaban a deslindarlo de otros géneros ya fundar una poética del mismo, en abierta pugna con el canon vigente. Tal fue el caso de las propuestas por Laurian Puerta, quien en la revista Zona, de Barranquilla publicó una especie de manifiesto en el que el minicuento adquiría una "función literaria subversiva":

"Sacado de una de sus falsas costillas, el minicuento, ese extraño género del siglo XX, ha conducido al cuento clásico al camino de una estrepitosa bancarrota. Parece una afimación temeraria. Pero es una rebelión 
inexorable que viene gestándose desde la cuentística inaugurada por Poe. La primera escaramuza fue con el relato breve. Y al minicuento se le ha encomendado la delicada misión de darle el tiro de gracia" (Valadés, 1990: 28).

La "rebelión" artística se hacía aún más "beligerante" con consignas del estilo: “iNi un paso atrás, siempre en el minicuento!", a las que se agregaban principios conminatorios como los que siguen:

"Concebido como un híbrido, un cruce entre el relato y el poema, el minicuento ha ido formando su propia estructura. Apoyándose en pistas certeras se ha ido despojando de las expansiones y las catálisis, creando su propia unidad lógica, amenazada continuamente por lo insólito que lleva guardado en su seno. La economía del lenguaje es su principal recurso, que revela la somresa o el asombro. Su estructura se parece cada día a la del poema. La tensión, las pulsaciones internas, el ritmo y lo desconocido se albergan en su vientre para asaltar al lector y espolearle su imaginación. Narrado en un lenguaje coloquial o poético, siempre tiene un final de puñalada. Es como pisarle la cola a un alacrán para conocer su exacta dimensión... El cuento clásico ha sido domesticado, convertido en una sucesión de palabras sin encantamientos. El minicuento está llamado a liberar las palabras de toda atadura. Y a devolverle su poder mágico, ese poder de escandalizarnos... Diariamente hay que estar inventándolo. No posee fórmulas o reglas y por eso permanece silvestre o indomable. No se deja dominar ni encasillar y por eso tiende su puente hacia la poesía cuando le intentan aplicar nomas académicas" (Valadés, 1990: 28).

En opinión de Valadés el aguerrido manifiesto de Puerta "no deja de ser otra certitud del auge de los significados actuales del cuento brevísimo, que encuentra allí partidarios que lo enarbolan como desideratum cuentístico" (1990: 28).

\section{El Minicuento en la Literatura Colombiana Actual}

En la ardua lucha de géneros que se aprecia en la literatura colombiana, la novela sigue victoriosa. Sin embargo, algunos géneros considerados como marginales, entre ellos el minicuento, han venido ganando terreno en los últimos años, hasta lograr su reconocimiento y plena aceptación, lo cual se manifiesta en la acogida que se le ha dis pensado al microrrelato en diferentes ámbitos culturales.

A diferencia de las etapas antes descritas en las que escaseaba la edición de minicuentos, en la actualidad es posible encontrar en librerías múltiples ediciones de antologías u obras de autores individuales integradas por minicuentos. A nivel académico, también se le viene concediendo gran importancia a la ficción brevísma, aunque en forma genérica, ejemplo de lo cual son los trabajos de Nana Rodríguez, Elementos para una teoría del minicuento (1996); Angela María Pérez 
Beltrán Cuento y miniCuento (1997); y, Rodrigo Díaz Castañeda y Carlos Parra Rojas, Breve teoría y antología sob re el minicuento latinoamericano (1997), que se originaron como tesis de postgrado y terminaron convirtiéndose en libros. Publicaciones a las que se suma Antología del Cuento Corto Colombiano, una obra que recoge muchos de los minicuentos publicados por la revista Ekuóreo, durante sus años de circulación, a la que sus autores Guillemo Bustamante y Harold Kremer, agregan una breve introducción dedicada a la reseña histórica del minicuento.

En la parte inventiva se aprecia el cruce de dos generaciones de minicuentis tas: la primera, constituida por los ya consagrados y reconocidos como Jairo Anibal Niño, David Sánchez Juliao, Celso Román, Triunfo Arciniegas, Elkin Restrepo, Jaime Castaño, Guillemo Velásquez, Juan Carlos Botero, Carlos Flaminio Rivera, Nicolás Suescún, Luis Fayad, Marco Tulio Aguilera, Juan Carlos Moyano, Jaime Alberto Vélez, Javier Tafur, Andrés Elías Florez, Harold Kremer, Fernando Ayala, Germán Santamaría, Camen Cecilia Suárez y Fanny Buitrago, entre otros, quienes continúan en plena actividad, a la par de los cuales se encuentran autores de publicación reciente como Nana Rodríguez, Pablo Montoya, Guillemo Bustamante, Gabriel Pabón, Juan Federico Torres, Carlos Arturo Ramírez, César Jair Ariza y muchos más, que harían es ta lista sumamente amplia.

Otra de las actividades que estimulan y difunden el minicuento son los concurs os institucionalizados, entre ellos el realizado anualmente por la Alcaldía Mayor de Bogotá y dedicado a diferentes modalidades artísticas, entre ellas el cuento y el minicuento. También es pertinente mencionar el Concurso Departamental de Minicuentos, con sede en el municipio de Palemo, Departamento del Huila, que tiene varias ediciones. Además existen otros concursos convocados de manera coyuntural por universidades, casas de la cultura, periódicos y revis tas. Entre ellos cabe nombrar El mínimo esfuerzo, concurso efectuado en el año 2000 por la Revista elmalpensante, una de las publicaciones culturales colombianas de circulación nacional e intemacional más importantes, en el cuál resultó vencedor el escritor antioqueño Elkin Obregón, y, el Concurso de Cuento Breve realizado por el periódico El Tiempo durante el año 2001, del cual salió ganador el escritor Roberto Rubiano.

El panorámico recuento de esta etapa del minicuento en la literatura colombiana quedaría incompleto sin la mención de otras actividades culturales que han contribuido a su creación y difusión, como la amplia acogida que está teniendo en los textos escolares, que han reemplazado el fragmento de cuentos o novelas por el minicuento. También, el registro del Record Guines de José Ordóñez, un humorista que disolviendo las fronteras entre el chiste y el minicuento alcanzó 72 horas continuas contando historias en la radio; o el recorrido por filas de cineclubes y vehículos del transporte urbano que hasta hace pocos años hacía el escritor Jaime Castaño en procura de vendersus minicuentos.

A lo anterior se suma el retorno del minicuento a la tradición oral en espacios muy diversos tal y como se ilustra en la anécdota del escritor Jairo Anibal Niño, quien 
fue a Villavicencio a buscar un puesto de ventas callejero que le había mencionado un amigo. Alí efectivamente, encontró al vendedor ambulante que ofrecía "jugos con cuento", que incluían una breve historia contada por él mientras el cliente tomaba el jugo; por supues to, estos eran más costos os que los "jugos sin cuento". Lo curioso del hecho es que la mayoría de es tos minicuentos orales eran tomados de algunos de los libros que el escritor había publicado y el vendedor los reivindicaba como propios, ante lo cual Jairo Aníbal se limitó a pedir suficientes jugos para beberlos mientras disfrutaba la apropiación popular de su trabajo que permitía a otros a escuchar los minicuentos que no leían.

Ins istiendo en la esencia preliminar de estas reflexiones solo restaría decir que en Colombia la creación breve tiene una importante trayectoria a la espera de ser historiada, as unto que ya hemos empezado y en el que esperamos avanzar en poco tiempo, con el fin de revelar esa gran riqueza imaginativa que existe en nuestro país en torno al minicuento y que se proyecta día a día con nuevos y jóvenes talentos.

\section{BIBLIOGRAFÍA}

BUSTAMANTE, Guillermo y KREMER, Harold. (Antologis tas) (1994) Antología del cuento corto colombiano. Cali: Universidad del Valle.

BUSTAMANTE, Guillermo (Bogotá) Ekuóreo: Una historia por re-contruir. A propósito del mini-cuento en Colombia. Texto inédito cedido por el autor para el presente estudio.

DÍAZ CASTAÑEDA, Rodrigo y PARRAROJAS, Carlos (1997) Breve teoría y antología sobre el minicuento latinoamericano. Neiva: ACE Samán EditoresUniversidad Surcolombiana.

NÚMERO MONOGRÁFICO DEDICADO AL MINICUENTO (1996), Revista Interamericana de Bibliografía. Washington, D.C.: OEA, XL VI, 1-4

PEÑA, Isaías (1986) Prólogo. En Suenan Timbres. Bogotá: Plaza y Janés.

PEREZ BELTRAN, Angela María (1997) Cuento y minicuento. Bogotá: Página Maestra Editores.

POLLASTRI, Laura (1998) El breve puente del relato breve. Literatura: Espacio de contactos culturales. Memorias de las IV Jornadas Nacionales de Literatura Comparada. San Miguel de Tucumán, 12-15 de agos to de 1998.

RAMOS, Oscar Gerardo (1968) El Carnero libro único de la Colonia. Medellín: Editorial Bedout. 
RODRÍGUEZ, Nana (1996) Elementos para una teoría del minicuento. Tunja: Colibrí Ediciones.

ROJO, Violeta (1997) Breve manual para reconocer minicuentos. México: Universidad Autónoma Metropolitana.

TOMASSINI, Graciela y MARIS COLOMBO, Stella (1996) La minificción como clase textual transgenérica. En Revista Interamericana de Bibliografía.

$X L V I, 1-4$. Washington, D.C.: OEA.

TOMASSINI, Graciela y MARIS COLOMBO, Stella (1998) Comprensión Lectora y Producción Textual. Minificción Hispanoamericana. Córdoba-Rosario: Editorial Fundación Ross.

VALADÉS, Edmundo. (1990) Ronda por el cuento brevís imo. En Revista Puro cuento, 21, 28-30.

VID ALES, Luis. Suenan Timbres. [1926]. Bogotá: Colcultura, 1976. 198 págs.

ZAVALA, Lauro (2000) Relatos vertiginosos. Antología de cuentos mínimos. México: Alfaguara. 